\title{
Cognitive Fusion on Counselor Performance: A Comparative Study of the Experienced and Novice Counselor
}

\author{
Husni Hanafi ${ }^{1 *}$, Nur Hidayah ${ }^{2}$, Adi Atmoko ${ }^{3}$, M. Ramli ${ }^{4}$, Triyono $^{5}$ \\ ${ }^{1}$ Guidance and Counseling Department of State University of Malang, Karangbesuki Malang, Indonesia, \\ ${ }^{2}$ Guidance and Counseling Department of State University of Malang, Tlogomas Malang, Indonesia, \\ ${ }^{3}$ Guidance and Counseling Department of State University of Malang, Wagir Malang, Indonesia, \\ ${ }^{4}$ Guidance and Counseling Department of State University of Malang, Klojen Malang, Indonesia, \\ ${ }^{5}$ Guidance and Counseling Department of State University of Malang, Lowokwaru Malang, Indonesia,
}

\begin{abstract}
The counselor's internal competence has an impact on the counselor's self-management, primarily the cognitive domain. Failure to manage thoughts will cause cognitive distortions, even to identify biases in mental experiences. This condition is cognitive fusion. Cognitive fusion causes the counselor to be trapped in his mind, unable to discern the effects of his mind's external assumptions on conditions. The experienced counselor can predict the counselor's cognitive fusion condition. This study aims to identify and describe the cognitive fusion condition data for counselors. The research method uses a comparative study design through the Cognitive Fusion Questionnaire instrument. Respondents in this study totaled 170 divided into two groups, experienced counselors and novice counselors. The moderate form of counselors' cognitive fusion condition was found as the research results. In particular, some counselors have high cognitive fusion conditions. The counselor's experience in counseling, evaluation, supervision, and action research makes them train their minds to think at a high level. Thus, the counselor has many historical events as their reflection and internalization in their mind. Based on the research results, Mind-skills training could be given as one of recommendation to improve the metacognitive skills of novice counselors so that they can match the performance of experienced counselors.
\end{abstract}

Keywords: Cognitive fusion, Counselor internal competencies, Metacognition.

\section{INTRODUCTION}

Internal competence is one of the essential competencies that counselors need to have. Internal competence plays a role in providing services paradigmatic and theoretical and the counselor's self-management process in communication and therapeutic relationships (American Psychological Association, 2015; Wyrick et al., 2014). Internal competence is not like knowledge related to counseling paradigms and theories, but internal competence on how counselors have optimal internal conditions to be realized in counseling services (Ramli et al., 2018).

The non-optimal condition of the counselor's internal state can lead to many symptoms that interfere with the counseling process. Symptoms of these disorders often appear in the form of cognitive distortions or impaired thinking counselors (Chen et al., 2016). Cognitive distortion experienced by the counselor is not a severe problem condition as experienced by the counselee. However, these conditions hinder the process of internal counselors and ultimately help the counseling process.

The counselor's advisory distortion is an actual manifestation of the weak management of the counselor internal conditions (Hidayah, 2010)since the enactment of government decree number 27 of 1981 on the restructuring of faculty and departments, and public law number 14 of 2005 on teachers and university lecturers, which stipulate academic qualification were represented by any S-1 certificates, or any D-IV certificates while the teacher competence were nurtured true the professions of curriculum materials (Content-Transmission Paradigm. As a result, the counselor's internal condition is not in ideal state for providing counseling services. These conditions can impact conditions of confusion, stressful, negative countertransference, burnout, and anxiety in the counselor. The obstacle to the

Corresponding Author e-mail: hanafihusni.1901119@students. um.ac.id

https://orcid.org/0000-0002-9772-5723

How to cite this article: Hanafi $\mathrm{H}$, Hidayah $\mathrm{N}$, Atmoko A, Ramli M, Triyono (2022). Cognitive Fusion on Counselor Performance: A Comparative Study of the Experienced and Novice Counselor. Pegem Journal of Education and Instruction, Vol. 12, No. 1, 2022, 48-55

Source of support: We thank you for the funding from the Directorate of Research and Community Service (DRPM)represented by Research and Community Service State University of Malang (LP2M UM). We are helpful by the funding to our research, in the writing of the report; and in the decision to submit the article for publication.

Conflict of interest: None.

DOI: 10.47750/pegegog.12.01.06

Received: 19.08 .2021

Accepted: 03.11.2021 Publication: 01.01.2022 
internal counselor process focuses on the failure of the counselor's mind management process.

One form of failure to manage the counselor's mind, especially in terms of thought content, is a cognitive distortion in the form of cognitive fusion. Cognitive fusion exhibits psychological inflexibility, excessive adherence to rigid verbal rules, and causes psychological distress (Gillanders et al., 2014) |"defusion|" interventions aim to l"unhookl" thoughts from actions and to create psychological distance between a person and their thoughts, beliefs, memories, and selfstories. A number of similar concepts have been described in the psychology literature (e.g., decentering, metacognition, mentalization, and mindfulness. Cognitive fusion shows a failure to distinguish between thought processes, experiences, and emotional reflections that occur in him (García-Gómez et al., 2019). Cognitive fusion in a counselor can cause the counselor to be trapped in his internal experiences and cannot objectively assess the condition of the counseling process.

In the study of Acceptance and Commitment Therapy, an individual who experiences cognitive fusion is more entangled in the content of their thoughts and avoids their internal experiences (such as rational thinking, emotion, awareness, and memory) (Dinis et al., 2015). This entanglement causes unproductive cognitive activities to prevent other inner experiences. In these conditions, the counselor may lose focus and objectivity during the counseling process.

The counselor's internal condition management becomes an effective form of internal counselor competence to improve the counseling service. Metacognition skills become an alternative to be able to manage the condition of the internal counselor. The counselor's metacognition in the counseling process can appear in various forms. One of the findings that shows a structure of counselor metacognition is mind skills (Hanafi, Hidayah, Atmoko, \& Ramli, 2021; Radjah, 2016). In the previous study, Nelson-Jones' construct of Mind skills (Nelson-Jones, 2006, 2014) adapted to the counselor's metacognition process.

Other factors, such as experience, can also influence the counselor's metacognitive process. The counselor's experience is the basis for the idea that internal competence needs more than education and practice for prospective counselors (Hidayah et al., 2021; Ridley et al., 2011). Like other competencies and skills, internal competence requires experience in processing and reflecting on any necessary counseling process. Metacognition are contributing to the reflecting process as their autonomous learning from their experience (Khulaifiyah et al., 2021). Furthermore, the results of these reflections could be a base to improve the performance of the counseling provided.When internal conditions are well managed, especially in avoiding cognitive fusion, the counselor can see objectively between thoughts, feelings, and other inner experiences exists (i.e., verbally entangled learning processes) and assumptions (e.g., the world) (Hapenny \& Fergus, 2017). Thus, counselor can understand the structured reality which is unfounded. This state manifests cognitive defusion, where individuals have successfully carried out the metacognition process to decentralize their thoughts and internal experiences (Bernstein et al., 2015).

The cognitive defusion state will increase empathy, unconditional positive regard, and the counselor's sensitivity towards the state of the counselee and the counseling situation (Krafft et al., 2019). Specifically, the impact of performance in the form of, in particular, strengthening the involvement and involvement of counselors in the counseling process. Indirectly, this condition will also reduce the possibility of breaking the counselee's engagement and the process of early termination of counseling (Chen et al., 2016; Elkin et al., 2014).

The previous studies and ideas place cognitive fusion as a process that every counselor needs to avoid. Therefore, the cognitive fusion condition of the counselor becomes a study that has the urgency to be identified. This identification can lead to the experienced counselor's ability to manage their thought processes, explicitly avoiding cognitive fusion. This identification becomes more critical when counselors who can avoid cognitive fusion can manage their thought processes to be "attune" and "reach" the counseling process, situation and relationship (Atzil-slonim et al., 2015).

This research aims to identify the difference in cognitive fusion state of novice counselors and experienced counselors. This research questions the difference because of experience in managing counselor thought, especially on cognitive fusion. Furthermore, this study has a hypothesis $\left(\mathrm{H}_{0}\right)$ "there are differences in the data in the experienced counselor group and the beginner group". Meanwhile, the opposite view $\left(\mathrm{H}_{\mathrm{a}}\right)$ states that "there is no difference in data between the two groups of counselors". Furthermore, some experiences influence the process of managing the state of internal counselor factors. Identification of cognitive fusion conditions for experienced counselors will be a study that can identify the need for counselors' training to manage their thought and be fully cognitively involved in their performance.

\section{Method}

This study aims to identify the cognitive fusion condition of counselors and compare two cognitive fusion conditions between experienced and novice counselors. Following these objectives, this study uses a non-experimental quantitative research method with a comparative study design. Comparative studies aimed to find and compare two variables (Creswell et al., 2003).

\section{Data Sample}

This study has a population of all counselors in East Java, Indonesia. Due to a large number of populations, the subject's 
selection used cluster-random sampling methods. Two clusters in the sample of respondents are counselors with more than five years of experience and novice counselors. Based on this process, 170 counselor samples were obtained with 85 experienced counselors and 85 novice counselors.

\section{Instrument}

Furthermore, measurements were carried out through a questionnaire instrument. The questionnaire used is a cognitive fusion questionnaire instrument. The questionnaire uses a Likert scale to measure the level of appropriateness of the cognitive fusion condition in every respondent. The cognitive fusions element explained by Gillanders et al. (2014)|"defusion|" interventions aim to l"unhookl" thoughts from actions and to create psychological distance between a person and their thoughts, beliefs, memories, and selfstories. A number of similar concepts have been described in the psychology literature (e.g., decentering, metacognition, mentalization, and mindfulness became the indicators of the questionnaire construct. These elements are (1) Over Believability of thoughts; (2) Taking thoughts literally; (3) Reacting emotionally to thoughts; (4) Behavior being governed by thoughts; (5) Avoiding to control thoughts; (6) Overanalyzing situations; (7) Avoiding Evaluate thought content; (8) Dominance of cognition in a person's experience; (9) Absolute Perspective taking; and (10) Detached awareness of thoughts. The cognitive fusion questionnaire has 20 items with four level of options. These four options are Very Appropriate, which has a score of 4; Appropriate, which has a score of 3; Less Appropriate, which has a score of 2; and Inappropriate, which has a score of 1 points. The questionnaire's score was then used for the mean analysis and the percentage of the 80 maximum scores. The cognitive fusion questionnaire has relatively high reliability with a Cronbach alpha coefficient of 0.705 (above the minimum number of 0.6 ). The cognitive fusion questionnaire also has high validity on each item with a significance at 0.01 and 0.05 levels (2-tailed) based on Pearson correlation analysis.

\section{Data Analysis}

The process of the analysis of the instrument filling using descriptive statistics and comparative independent sample T-test. The independent sample T-test compares the mean of two data groups (Ross \& Willson, 2017)a theory may predict that one group will have higher scores on average than another group. In a situation like that the researcher is asked to decide whether the results they actually get fit the pattern of results predicted by the theory. This decision could be made by looking at the means for the two groups and thinking, in a subjective or intuitive way, about whether the mean for group $\mathrm{A}$ is far enough above the mean of group B for it to be believable that the prediction made by the theory has been supported by the evidence. But psychologists, as scientists, would rather have a way of making these decisions that is more precise than this. Certainly, one person's subjective decision might be different from another person's subjective decision. Tools of statistical inference are useful because they are based on very clearly defined rules for deciding whether or not the predictions of an experimenter are supported by the data. In the sections to follow, we will see how psychologists (a. The initial analysis results describe the counselor's cognitive fusion state in the form of averages and percentages. The following data is then shown in graphical form. Comparative test analysis showed differences between the cognitive fusion condition scores of each group of experiential counselors and counselors' data.

\section{FINDINGS}

\section{Overall Description of Cognitive Fusion State of the Counselors}

The research results have identified the overall description of the cognitive fusion condition. The data shows there are various states based on every aspect of cognitive fusion. In more detail, Figure 1 and Table 1 show the data results.

Based on Figure 1., the data shows the main state of counselor cognitive fusion in the range of $50-60 \%$. Nearly half of the respondents ( 83 counselors) are in that range. This condition shows the cognitive fusion state at a moderate level.

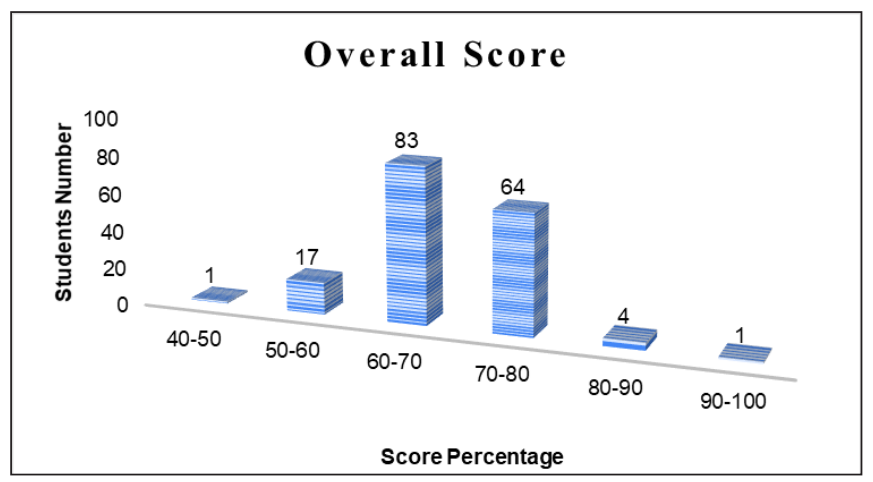

Fig. 1: Counselor Cognitive Fusion Overall Score.

Table 1: The Overall Counselor Cognitive Fusion.

\begin{tabular}{ll}
\hline Cognitive Fusion Element & Percentage \\
\hline Over Believability of thoughts & $70.235 \%$ \\
Taking thoughts literally & $65.262 \%$ \\
Reacting emotionally to thoughts & $58.771 \%$ \\
Behavior being governed by thoughts & $84.669 \%$ \\
Avoiding to control thoughts & $53.384 \%$ \\
Overanalyzing situations & $80.801 \%$ \\
Avoiding Evaluate thought content & $77.003 \%$ \\
Dominance of cognition in a person's experience & $70.235 \%$ \\
Absolute Perspective taking & $55.594 \%$ \\
Detached awareness of thoughts & $61.740 \%$ \\
\hline
\end{tabular}


In the average number, the total number of counselors showed the state in the percentage of $67.769 \%$. This percentage has an interpretation that cognitive fusion is still an obstacle in the counselor's performance. Meanwhile, in the data exposure for each element of cognitive fusion, the elements "Behavior being governed by thought" and "Overanalyzing situation" are the two highest elements experienced by the total population.

\section{Data Description of the Experienced Counselors and Novice Counselors}

The following results of the study are a more specific identification of the cognitive fusion conditions of experienced counselors. As a comparative study, the research data also identified specific cognitive fusion conditions of novice counselors. The following results will be the basis for the comparison of the two groups of subjects. The presentation of data on the state of cognitive fusion for experienced counselors is in Figure 2 and Table 2.

Figure 2 data shows differences and gain scores that vary in each category of cognitive integration. However, the percentage achievement of $60-70 \%$ has a slight difference.

In the cognitive fusion element in Table 2, both of them show the highest achievement in the aspect "Behavior is governed by the mind". In the data, while for experienced counselors, the lowest score for cognitive fusion conditions

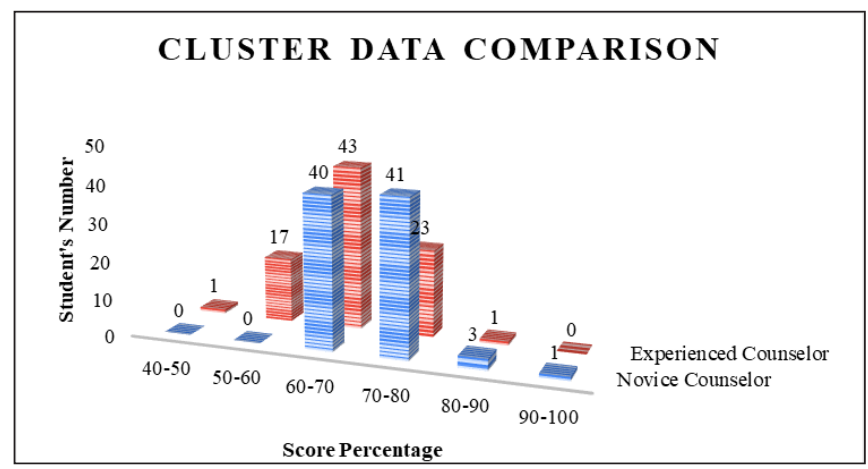

Fig. 2: Counselor Cognitive Fusion Comparison Score is $49.290 \%$, for novice counselors, the lowest percentage is $57.25 \%$. The two lowest scores are on the same element, namely "Avoiding mind control".

\section{Comparative Test Results of the Experienced Counselors and Novice Counselors}

Compartive analysis show the difference beetwen cognitive fusion state of the experienced and novice counselor. The analysis results are in Table 3 and Table 4.

Based on the comparative test data in table 4, the analysis results show significance in the column "Assumption of the same variance" at 0.0004 . This figure is below the coefficient of 0.05 , indicating a significant difference between the two data groups. The following comparative test data also describes the average comparison of experienced counselors of $-5.191 \%$. Thus, the conclusions obtained from the data indicate that there is a cognitive fusion condition in experienced counselors and novice counselors.

\section{Discussion}

The results showed differences in cognitive fusion conditions in the minds of novice counselors and experienced counselors. Experienced counselors overall have a lower level of cognitive fusion. Some novice counselors show very high cognitive fusion achievements. However, overall there are only a few counselors who experience low cognitive fusion. The result of the study shows the urgency to improve the counselor's internal competencies, primarily to manage their thought and reduce their cognitive fusion.

The experienced counselor shows their lowest cognitive fusion state at the "Avoiding to control thoughts" element in more detail. The lowly state of this aspect shows that the experienced counselor has tried to manage their thinking. Another element at an almost low state is "Reacting emotionally to thoughts" and "Absolute Perspective taking." The experienced counselor shows their effort to react wisely and have cognitive flexibility. On the other hand, the "Behavior

Table 2: The Comparison Counselor Cognitive Fusion.

\begin{tabular}{lll}
\hline Cognitive Fusion Element & Experienced Counselor Percentage & Novice Counselor Percentage \\
\hline Over Believability of thoughts & $70.028 \%$ & $70.430 \%$ \\
Taking thoughts literally & $63.778 \%$ & $66.667 \%$ \\
Reacting emotionally to thoughts & $52.983 \%$ & $64.247 \%$ \\
Behavior being governed by thoughts & $86.648 \%$ & $82.796 \%$ \\
Avoiding to control thoughts & $49.290 \%$ & $57.258 \%$ \\
Overanalyzing situations & $82.670 \%$ & $79.032 \%$ \\
Avoiding Evaluate thought content & $77.131 \%$ & $76.882 \%$ \\
Dominance of cognition in a person's experience & $65.057 \%$ & $75.134 \%$ \\
Absolute Perspective taking & $53.125 \%$ & $57.930 \%$ \\
Detached awareness of thoughts & $58.381 \%$ & $64.919 \%$ \\
\hline
\end{tabular}


Table 3: The Comparison Counselor Cognitive Fusion

\begin{tabular}{llllll}
\hline & Group & $N$ & Mean & Std. Deviation & Std. Error Mean \\
\hline \multirow{2}{*}{ Cognitive Fusion } & Experienced & 85 & 65.2500 & 6.59128 & .71492 \\
& Novice & 85 & 70.4412 & 4.84394 & .52540 \\
\hline
\end{tabular}

Table 4: The Comparison Counselor Cognitive Fusionw

\begin{tabular}{llll}
\hline & & \multicolumn{2}{c}{ CognitiveFusion } \\
\cline { 3 - 3 } $\begin{array}{l}\text { Levene's Test for Equality of } \\
\text { Variances }\end{array}$ & $\mathrm{F}$ & Equal variances assumed & Equal variances not assumed \\
\cline { 2 - 3 } & Sig. & 8.505 & \\
t-test for Equality of Means & $\mathrm{t}$ & 0.004 & -5.851 \\
& $\mathrm{df}$ & -5.851 & 154.244 \\
& Sig. (2-tailed) & 168 & 0 \\
& Mean Difference & 0 & -5.19118 \\
& Std. Error Difference & -5.19118 & 0.88722 \\
& $95 \%$ Confidence Interval of the & -6.94272 & -6.94385 \\
& Difference & -3.43964 & -3.4385 \\
\hline
\end{tabular}

being governed by thoughts" elements became the novice counselor's highest cognitive fusion state. This data shows that novice counselors act and behave based on their thought. Thus, when their thought at cognitive fusion state, their act and behavior are also disturbed.

Cognitive fusion occurs in 'stepping back' or yielding compelling beliefs (Sood \& Newman-Taylor, 2020). The failure of defusion, mental experiences, and real situations causes individuals fail to change their beliefs into adaptive and rational thoughts. This state became hard to change because their belief is based on personal evaluation and judgement than objective reality (Şahin, 2020). Changing the state of cognitive fusion through defusion can be done when the individual has a good consciousness.

Proper awareness is a broad construct that refers to witnessing thoughts and feelings as mental events as distinct from a true reflection of self or reality (Bernstein et al., 2015; Samadifard, 2017). Through this process, cognitive defusion emerged as enabling individuals to "see thoughts and feelings as they are (i.e., verbally entangled concept processes) rather than their assumptions (e.g., understood the world, structured reality)" (Hayes et al., 2011).

The achievement of cognitive defusion in the process gives rise to activities to consider the counseling relationship and focus attention on his thoughts as mental events (GarcíaGómez et al., 2019). This defusion increases the separation or discrimination of the mind, seeing it with the proper perspective and its reflection more adaptively. Thus, cognitive can reduce the automatic effect of verbal thought content so that other sources of regulation can participate better
(Samadifard \& Narimani, 2017) in eliciting adaptive attitudes and behaviors.

The decentering process becomes a higher-order thinking process of a counselor (Bernstein et al., 2019). The existence of mental activity that occurs in the counselor's internal self allows a mixed thought process. Higher-order thinking based on some confusion, doubt, or indecision becomes a process that avoids spontaneous combustion (Letseka \& Zireva, 2013) magnet resonance imaging. The counselor's higher-order thinking process needs to discriminate and manage mental events maturely and automatically.

Higher-order thinking processes in the form of metacognition require states of awareness of mental events that occur (Shetty, 2014). Without self-awareness, counselors can experience unconscious defensive processes that trigger cognitive fusion. Misattribution, distortion, or dysfunctional reduction of the phenomena encountered becomes a counselor characteristic who cannot realize his internal conditions (Rønnestad, 2016)). On the other hand, self-awareness in reflection and introspection became an ability to recognize and understand oneself (Masouleh et al., 2019). The process is based on full awareness to be able to sort out a mental event and another.

The condition of the counselor's full awareness of his internal and external conditions helps manage his internal condition so that the counselor can capture emotional sensations, thoughts, and images from himself and the counselee (Piedfort-Marin, 2019). At a more advanced level, counselors can use it in the process of confrontation and problem solving (Oddli \& Rønnestad, 2012). The internal 
process management involves a fundamental thought process: forming assumptions on the assimilation thinking from each mental counselor's experience (Hidayah, Ramli, et al., 2020; Hidayah, Yuliana, et al., 2020; Mensah \& Somuah, 2014). Counselors with high cognitive fusion failed to gain this process, ignoring the understanding of opposite mental sensations (Hanafi, Hidayah, Atmoko, Ramli, et al., 2021).

In metacognition studies, forming assumptions and assimilation thinking is the decentering model to respond to their thought process. At the same time, cognitive fusion is related to the failure of decentralizing thought (Bernstein et al., 2019). The decentering model of metacognition has three functions consisting of meta-consciousness (awareness of subjective experience), identification of internal affairs (experience of inner states as separate from oneself), and reduced reactivity to thought content (reducing the effect of thoughts on other mental processes). The Cognitive Fusion condition shows the failure of the metacognitive function on decentering model. The counselor's metacognition processes are unable to reflect increased reactivity to thought content.

The experienced counselor succeeded in managing their internal experience and sensations through reflecting in each counseling session (Bennett-levy \& Finlay-jones, 2018; Hidayah et al., 2018). This success establishes a higher existence, sensitivity, and awareness in the experienced counselor. The counselor's sensitivity and understanding are well-formed, able to grow the counselor's metacognition skills. In the other process, the counselor improves fast, flexible, and shrewd in managing his internal condition (Ambolt et al., 2017). This success makes the counselor able to diffuse his mind.

The cognitive defusion process is not about how long a person tries to manage their thought. However, the process of reflecting and internalizing every aspect of the counselor's experience is the difference between novice and experienced counselors (Baum, 2006; Gibson et al., 2009). Experienced counselors have a lot of historical reflection on their experiences; this at the same time also trains the counselor's accuracy and flexibility in managing his thoughts (Smith et al., 2007). On the other hand, novice counselors need extra effort and high skills to manage their thoughts quickly to gain the same particular competencies as experienced counselors.

The process of internal state reflection can be influenced by various factors, from evaluation and supervision processes (Mažgon et al., 2018; Schofield \& Grant, 2013) to research activities on the counseling process and itself to improve internally. In particular, supervision activities provide the chance for thorough reflection (Kernberg, 2019; Lysaker et al., 2019). Thus, the supervision activities need to add focus on assessing the counselor's internal competence. In addition, action research activities in the counselor's counseling process can be an alternative and a suggestion for counselors to evaluate and reflect their experience themselves individually (Hunter, 2017).
The counselor's metacognitive competence training is another alternative for novice counselors, even prospective counselors. This process provides higher-order thinking skills in thinking about what the counselor is thinking (Hanafi et al., 2020; Konarski \& Brycz, 2017). In previous researchers' studies, the students counselor can also improve their metacognition by training their mind skills (Hanafi, Hidayah, Atmoko, \& Ramli, 2021; Hidayah, 2010; Radjah, 2016).

\section{Conclusion}

The data research shows the difference between experienced and novice counselors, primarily in their cognitive fusion state. The experienced counselor has trained their skills to manage their mind in the evaluation and reflection process. In every experience, a counselor should evaluate their performance, including their mind, and try to expertise their ability to manage their mind. The reflective process became one of the requirement-supported skills. Nevertheless, the experienced counselor still has their cognitive fusion as their distraction. After all, the metacognition skills are the alternative skills to defuse their mental by using the decentering model. As a form of metacognition, the counselor should train their mind skills.

\section{Limitation and Suggestion}

The limitations of this study are the detailed contribution of the counselor's experience form. It limits the specific results of the contribution of counselor experience managing their cognitive fusion. In addition, the research sample of experienced counselors is still limited in terms of time and length of service as school counselors. This study has not identified other forms of experience such as education and training experience, institutional experience at the educational level, and experience in various schools.

Suggestions for further research are to focus more on assessing other forms of experience on counselors' cognitive fusion management skills. In addition, the assessment of the counselor's metacognition forms on managing their cognitive fusion also given as a suggestion for further research. In the state of practical implications, the results of this study provide recommendations in developing models of education and training for prospective counselors. The Model developed should include metacognition skills training to manage counselor thinking processes to minimize the gap for novice counselors from the experience side.

\section{References}

Ambolt, A., Gard, G., \& Hammarlund, C. S. (2017). Therapeutically efficient components of Basic Body Awareness Therapy as perceived by experienced therapists - A qualitative study. Journal of Bodywork and Movement Therapies, 21(3), 503-508.

American Psychological Association. (2015). Competencies for Psychology Practice in Primary Care 1 Report of the 
Interorganizational Work Group on Competencies for Primary Care Psychology Practice. http://www.apa.org/ed/resources/ competencies-practice.pdf.

Atzil-slonim, D., Bar-kalifa, E., Lutz, W., Rubel, J., Schiefele, A., \& Peri, T. (2015). Therapeutic Bond Judgments : Congruence and Incongruence. Journal of Consulting and Clinical Psychology, 83(4), 773-784.

Baum, N. (2006). Therapists' Responses to Treatment Termination: An Inquiry into the Variables that Contribute to Therapists' Experiences. Clinical Social Work Journal 2006 35:2, 35(2), 97-106.

Bennett-levy, J., \& Finlay-jones, A. (2018). The role of personal practice in therapist skill development : a model to guide therapists, educators, supervisors and researchers. Cognitive Behaviour Therapy, 47(3), 185-205.

Bernstein, A., Hadash, Y., \& Fresco, D. M. (2019). Metacognitive processes model of decentering: emerging methods and insights. In Current Opinion in Psychology (Vol. 28, pp. 245-251). Elsevier B.V.

Bernstein, A., Hadash, Y., Lichtash, Y., Tanay, G., Shepherd, K., \& Fresco, D. M. (2015). Decentering and Related Constructs: A Critical Review and Metacognitive Processes Model. Perspectives on Psychological Science, 10(5), 599-617.

Chen, R., Atzil-slonim, D., Bar-kalifa, E., Hasson-ohayon, I., \& Refaeli, E. (2016). Therapists' recognition of alliance ruptures as a moderator of change in alliance and symptoms. Psychotherapy Research, Online, DOI: 10.1080/10503307.2016.1227104

Creswell, J. W., Clark, V. L. P., Gutmann, M., \& Hanson, W. E. (2003). Advanced mixed methods research designs. In Handbook of Mixed Methods in Social and Behavioural Research.

Dinis, A., Carvalho, S. A., Gouveia, J. P., \& Estanqueiro, C. (2015). Shame Memories and Depression Symptoms: The Role of Cognitive Fusion and Experiential Avoidance | IJPSY. International Journal of Psychology and Psychological Therapy, 15(1), 63-86. https://www.ijpsy.com/volumen15/num1/404.html

Elkin, I., Falconnier, L., Smith, Y., Canada, K. E., Henderson, E., Brown, E. R., \& McKay, B. M. (2014). Therapist responsiveness and patient engagement in therapy. Psychotherapy Research, 24(1), 52-66.

García-Gómez, M., Guerra, J., López-Ramos, V. M., \& Mestre, J. M. (2019). Cognitive fusion mediates the relationship between dispositional mindfulness and negative affects: A study in a sample of spanish children and adolescent school students. International Journal of Environmental Research and Public Health, 16(23).

Gibson, D., Velde, B., Hoff, T., Kvashay, D., Manross, P. L., \& Moreau, V. (2009). Clinical Reasoning of a Novice versus an Experienced Occupational Therapist: A Qualitative Study. Occupational Therapy In Health Care, 12(4), 15-31.

Gillanders, D. T., Bolderston, H., Bond, F. W., Dempster, M., Flaxman, P. E., Campbell, L., Kerr, S., Tansey, L., Noel, P., Ferenbach, C., Masley, S., Roach, L., Lloyd, J., May, L., Clarke, S., \& Remington, B. (2014). The Development and Initial Validation of the Cognitive Fusion Questionnaire. Behavior Therapy, 45(1), 83-101.

Hanafi, H., Hidayah, N., Atmoko, A., \& Ramli, M. (2021). Identification Counselor-Student's Mind Skills As Their Metacognitions Level In Counseling Process. International Conference on Learning Innovation (ICLI 2021), in press.
Kariyev A. D; Kodoeva A. C.; Fadeeva V. V.; Grigorev A. N; Akhmetov T.; Sardarova Z.; Yegenissova A. K.; Zhubangalieva G. G.. "The Formation of the Student's Objectivity in the University Educational Process". Journal for Educators, Teachers and Trainers, 11, 1, 2020, 13-18. doi: 10.47750/jett.2020.11.01.002

Hanafi, H., Hidayah, N., Atmoko, A., Ramli, M., \& Triyono. (2021). Measuring Cognitive Fusion on Counselor Involvement Performance. International Conference on Education and Technology (ICET), in press.

Hanafi, H., Hidayah, N., Triyono, Mappiare-AT, A., \& Atmoko, A. (2020). Belief System on Multicultural Counseling: Literature Review of Positive Belief System of Nusantara Culture. 1st International Conference on Information Technology and Education (ICITE 2020), 197-201.

Hapenny, J. E., \& Fergus, T. A. (2017). Cognitive fusion, experiential avoidance, and their interactive effect: Examining associations with thwarted belongingness and perceived burdensomeness. Journal of Contextual Behavioral Science, 6(1), 35-41.

Hayes, S. C., Strosahl, K. D., \& Wilson, K. G. (2011). Acceptance and commitment therapy: The process and practice of mindful change. Guilford Press.

Hidayah, N. (2010). Process-Audit Dalam Penyelenggaraan Pendidikan Akademik Jenjang S-1 Bimbingan Dan Konseling. Jurnal Pendidikan Dan Pembelajaran Universitas Negeri Malang, 17(2), 129-139.

Hidayah, N., Ramli, M., Fauzan, L., Rahman, D. H., Hanafi, H., Rofiqoh, \& Yunita, M. (2021). The Effect of Mind Skills on Student Counseling Cognitive Performance. International Conference on Education and Technology (ICET), in press.

Hidayah, N., Ramli, M., \& Hanafi, H. (2018). Cognitive-Behavioral Counseling Model Based on Local Wisdom at East Java. Proceedings of the 2nd International Conference on Learning Innovation (ICLI 2018), 109-113.

Hidayah, N., Ramli, M., Mappiare-AT, A., Hanafi, H., Yuliana, A. T., Kurniawan, N. A., \& Eva., N. (2020). Developing Critical Thinking Skills Test In Indonesia. Palarch's Journal of Archaeology Of Egypt/Egyptology, 17(3), 815-826.

Hidayah, N., Yuliana, A. T., \& Hanafi, H. (2020). Theoretical Validity of Problem Focused-Coping Skill Guideline to Develop Students' Critical Thinking Skills. Jurnal Kajian Bimbingan Dan Konseling, 5(4), 183-191.

Hunter, W. J. (2017). Evidence-based teaching in the 21st Century: The missing link . Canadian Journal of Education/Revue Canadienne De l'éducation, 40(2), 1-6. https://journals.sfu.ca/ cje/index.php/cje-rce/article/view/3106

Kernberg, O. F. (2019). Reflections on Supervision. American Journal of Psychoanalysis, 79(3), 265-283.

Khulaifiyah, Widiati, U., Anugerahwati, M., \& Suryati, N. (2021). Autonomous Learning Activities: The Perceptions of English Language Students in Indonesia. Pegem Journal of Education and Instruction, 11(3), 34-49.

Konarski, R., \& Brycz, H. (2017). Construct and Concurrent Validity of the Positive Metacognitions and Positive MetaEmotions Questionnaire in the Polish Population. SAGE Open, $7(2), 1-7$.

Krafft, J., Haeger, J. A., \& Levin, M. E. (2019). Comparing cognitive fusion and cognitive reappraisal as predictors of college student mental health. Cognitive Behaviour Therapy, 48(3), 241-252. 
Letseka, M., \& Zireva, D. (2013). Thinking: Lessons from John Dewey's How We Think. Academic Journal of Interdisciplinary Studies, 2(2), 51-60.

Lysaker, P. H., Buck, K. D., Pattison, M. L., Beasley, R. E., Hillis, J. D., \& Hamm, J. A. (2019). Supervision in the Psychotherapy of Schizophrenia: Awareness of and Mutual Reflection upon Fragmentation. American Journal of Psychoanalysis, 79(3), 284-303.

Masouleh, A. K., Mamat, M. Z. bin, \& Hasbullah, M. B. (2019). Exceeding Self-Awareness and Being Aware of the External World. Academic Journal of Interdisciplinary Studies, 8(4), 1.

Mažgon, J., Jeznik, K., \& Ermenc, K. S. (2018). Evaluating Future School Counselors' Competences for Inclusive Education. SAGE Open, 8(4), 1-10.

Mensah, F., \& Somuah, B. A. (2014). Rapprochement between Piagetian and Vygotskian Theories: Application to Instruction. Academic Journal of Interdisciplinary Studies, 3(1), 167-171.

Nelson-Jones, R. (2006). Human Relationship Skills: Coaching and Self-Coaching (4th ed.). Routledge.

Nelson-Jones, R. (2014). Practical counselling and helping skills : text and activities for the lifeskills counselling model (6th ed.). SAGE.

Oddli, H. W., \& Rønnestad, M. H. (2012). How experienced therapists introduce the technical aspects in the initial alliance formation: powerful decision makers supporting clients' agency. Psychotherapy Research: Journal of the Society for Psychotherapy Research, 22(2), 176-193.

Piedfort-Marin, O. (2019). When the therapist's traumas emerge in a psychotherapy session: The use of trauma-related countertransference. European Journal of Trauma \& Dissociation, 3(3), 181-189.

Radjah, C. L. (2016). Keterampilan Konseling Berbasis Metakognisi. Jurnal Kajian Bimbingan Dan Konseling, 1(3), 90-94.

Ramli, M., Hidayah, N., \& Fauzan, L. (2018). Effectiveness of structured learning approach to improve counselors' competence in applying solution-focused counseling. International Conference on Education and Technology.
Ridley, C. R., Mollen, D., \& Kelly, S. M. (2011). Beyond Microskills: Toward a Model of Counseling Competence. The Counseling Psychologist, 39(6), 825-864.

Rønnestad, M. H. (2016). Is Expertise in Psychotherapy a Useful Construct? Psychotherapy Bulletin, 51(1), 11-13.

Ross, A., \& Willson, V. L. (2017). Independent Samples T-Test. In A. Ross \& V. L. Willson (Eds.), Basic and Advanced Statistical Tests (pp. 13-16). Sense Publishers.

Şahin, F. (2020). Relationship between teachers' philosophical beliefs about education and their perceptions of school climate. Pegem Journal of Education and Instruction, 10(3), 635-654.

Samadifard, H. R. (2017). The Relationship between Cognitive Fusion, Meta-Cognitive Belief and Self-Compassion with Positive and Negative Affection in Female Teenagers. Academic Journal of Psychological Studies, 5(4). http://worldofresearches.com/ojs2.4.4-1/index.php/ajps/article/view/400

Samadifard, H. R., \& Narimani, M. (2017). The Role of Cognitive Belief, Fusion and Distortion in Predicting the General Health of Couples. In Journal of Community Health Research (Vol. 6, Issue 3). Journal of Community Health Research. www.SID.ir

Schofield, M. J., \& Grant, J. (2013). Developing psychotherapists' competence through clinical supervision : protocol for a qualitative study of supervisory dyads. BMC Pyschiatry, 13(12), 1-9.

Shetty, D. G. (2014). A Study of the Metacognition Levels of Student Teachers On The Basis Of Their Learning Styles. IOSR Journal of Research \& Method in Education (IOSRJRME), 4(1), 43-51.

Smith, A. J. M., Kleijn, W. C., \& Hutschemaekers, G. J. M. (2007). Therapist reactions in self-experienced difficult situations: An exploration. Counselling and Psychotherapy Research, 7(1), 34-41.

Sood, M., \& Newman-Taylor, K. (2020). Cognitive Fusion Mediates the Impact of Attachment Imagery on Paranoia and Anxiety. Cognitive Therapy and Research, 44(6), 1150-1161.

Wyrick, L., Mary, M., Greenwaldt, E., \& Gosselin, K. P. (2014). School Counselors' Perceptions of Competency in Career Counseling. The Professional Counselor, 4(5), 481-496. 